\title{
ASO Author Reflection: The End End of the Tower of Babel in Pseudomyxoma Peritonei
}

\author{
Álvaro Arjona-Sanchez, $\mathrm{PhD}^{1,2}$, Francisca Valenzuela-Molina, $\mathrm{MD}^{1,2}$, Blanca Rufian-Andujar, $\mathrm{MD}^{1,2}$, and \\ Antonio Romero-Ruiz, $\mathbf{P h D}^{1,2}$ \\ ${ }^{1}$ Unit of Surgical Oncology, Department of Surgery, Reina Sofia University Hospital, Córdoba, Spain; ${ }^{2}$ GE09 Research in \\ Peritoneal and Retroperitoneal Oncological Surgery, Maimonides Biomedical Research Institute of Córdoba (IMIBIC), \\ Reina Sofia University Hospital, University of Córdoba, Córdoba, Spain
}

Peritoneal pseudomyxoma (PMP) is a rare disease that is treated in referral centres via cytoreductive surgery in association with hyperthermic intraperitoneal chemotherapy (HIPEC). Given its particular biological and histological characteristics, the nomenclature used to describe PMP has not yet been standardized and therefore several histological classifications are available, including those by Ronnett et al. in $1995,{ }^{1}$ Bradley et al. in $2006,{ }^{2}$ the WHO classification published in $2010,{ }^{3}$ and the American Joint Committee on Cancer (AJCC) 8th edition in 2017. ${ }^{4}$ This Tower of Babel in PMP has made it very difficult to compare and share the data between different centres.

Regarding this issue, the Peritoneal Surface Oncology Group International (PSOGI) carried out a consensual classification system of PMP based on the DELPHI methodology. ${ }^{5}$ Most of the oncological surgeons adopted this new system, however no survival correlation had been studied. The present study has achieved this validation compared with the most used classification (Ronnett), obtaining an optimal level of prediction for overall survival and diseasefree survival in the receiver operating characteristic curves. ${ }^{6}$ This validation provides us with a trustworthy common language to deal with PMP, allowing us the possibility to perform collaborative studies on this rare disease.

After this validation study, we should take a leap forward by adding new prognostic factors, such as the molecular profile, including genetic mutations (Ras/Raf/ MEK/ERK pathway or TP53), and biomarkers, such as the

(C) Society of Surgical Oncology 2021

First Received: 4 January 2021

Accepted: 5 January 2021;

Published Online: 22 January 2021

Á. Arjona-Sanchez, $\mathrm{PhD}$

e-mail: alvaroarjona@hotmail.com
Ki67 proliferation rate used in other peritoneal malignancies. Including these molecular markers might provide us with a new score to predict outcomes for these patients.

DISCLOSURES Álvaro Arjona-Sanchez, Francisca ValenzuelaMolina, Blanca Rufian-Andujar, and Antonio Romero-Ruiz declare no conflicts of interest.

\section{REFERENCES}

1. Ronnett BM, Kurman RJ, Zahn CM, et al. Pseudomyxoma peritonei in women: a clinicopathologic analysis of 30 cases with emphasis on site of origin, prognosis and relationship to ovarian mucinous tumors of low malignant potential. Hum Pathol. 1995;26:509-24.

2. Bradley RF, Stewart JH 4th, Russell GB, et al. Pseudomyxoma peritonei of appendiceal origin: a clinicopathologic analysis of 101 patients uniformly treated at a single institution, with literature review. Am J Surg Pathol. 2006;30:551-9.

3. Carr NJ, Sobin LH. Adenocarcinoma of the appendix. In: FT Bosman, F Carneiro, RH Hruban, ND Theise, editors. WHO Classification of tumors of the digestive system. Lyon: IARC; 2010. p. 122-5.

4. Amin MB, Edge SB, Greene FL, et al. AJCC cancer staging manual. 8th edn. Berlin: Springer; 2017.

5. Carr NJ, Cecil TD, Mohamed F, et al. A consensus for classification and pathologic reporting of pseudomyxoma peritonei and associated appendiceal neoplasia: the results of the Peritoneal Surface Oncology Group International (PSOGI) modified delphi process. Am J Surg Pathol. 2016;40(1):14-26.

6. Rufian-Andujar B, Valenzuela-Molina F, Rufian-Peña S. From the Ronnett to the PSOGI classification system for pseudomyxoma peritonei: a validation study. Ann Surg Oncol. https://doi.org/10. 1245/s10434-020-09560-w.

Publisher's Note Springer Nature remains neutral with regard to jurisdictional claims in published maps and institutional affiliations. 